\begin{tabular}{|l|l|l||}
\hline \multicolumn{2}{|c|}{ PublisherInfo } \\
\hline \hline PublisherName & $:$ & BioMed Central \\
\hline \hline PublisherLocation & $:$ & London \\
\hline \hline PublisherImprintName & $:$ & BioMed Central \\
\hline \hline
\end{tabular}

\title{
CGH of invasive breast cancer
}

\begin{tabular}{||l|l|l||}
\hline \multicolumn{2}{|c||}{ ArticleInfo } \\
\hline \hline ArticleID & $:$ & 3667 \\
\hline \hline ArticleDOI & $:$ & $10.1186 /$ bcr-1999-66645 \\
\hline \hline ArticleCitationID & $:$ & 66645 \\
\hline \hline ArticleSequenceNumber & $:$ & 33 \\
\hline \hline ArticleCategory & $:$ & Paper Report \\
\hline \hline ArticleFirstPage & $:$ & 1 \\
\hline \hline ArticleLastPage & $:$ & 4 \\
\hline \hline & & RegistrationDate : 1999-12-23 \\
\hline ArticleHistory & $:$ & OnlineDate $\quad$ 1999-12-23 \\
\hline \hline ArticleCopyright & $:$ & Current Science Ltd1999 \\
\hline \hline ArticleGrants & $:$ & \\
\hline \hline ArticleContext & $:$ & 1305822 \\
\hline \hline
\end{tabular}




\section{Keywords}

breast cancer, CGH, cytogenetics

\section{Introduction}

Comparative genomic hybridization (CGH) provides a powerful method for identifying DNA copy number changes. Recently it has been shown that ductal carcinoma in situ (DCIS) is a genetically advanced lesion in which differences in morphology are mirrored by the variability of the associated genetic alterations. However, little is known about genetic changes and their correlation with specific morphological subtypes in invasive breast cancer.

\section{Aims}

To establish a model for the possible progression from the different subtypes of DCIS to invasive breast cancer.

\section{Comments}

This is a very good paper that adds further evidence to the hypothesis that breast cancer develops through several different genetic pathways. The frequent presence of 16q losses in low grade but not high grade breast tumours suggests a sequential progression is rather unlikely. Furthermore, the presence of $16 \mathrm{q}$ loss in low grade lesions suggests it may have a role in the very early manifestation of breast carcinogenesis.

\section{Methods}

Fresh frozen tissues from 77 cases of breast carcinoma were investigated. They comprised 40 invasive ductal, 14 lobular, 6 tubular, 9 tubulo-lobular and 8 mucinous carcinomas. Oestrogen and progesterone 
status was determined using immunohistochemistry. For each case 10 tissue sections were cut and DNA was extracted using proteinase $\mathrm{K}$ digestion followed by phenol-chloroform extraction. For CGH analysis the tumour DNA was labelled by a standard nick-translation reaction with biotin-16-dUTP. Labelled DNA fragments were purified by applying column chromatography. Digital image analysis and karyotyping were then performed. Furthermore fluorescence in situ hybridization (FISH) was carried out on three grade 3 invasive ductal carcinomas with 16q losses using probes specific for centromere 11 and $11 \mathrm{q} 13$.

\section{Results}

DNA copy number changes were present in most breast cancers with an average of 6.7 aberrations per case (range 0-20). The most frequent changes were losses of $8 p, 13 q$ and $16 q$ and gains of 1q, 3q, 8q, 1q and 20q. Amplifications were detected in 25 (32\%) cases, most frequently at 11q13, 17q12 and $20 \mathrm{q} 13$. Grade 1 well differentiated carcinomas averaged 3.6 aberrations per case and amplifications were detected in $18 \%$. The most frequent changes identified were at 1q (55\%), 8q (27\%) and 16q (45\%). Tubular and tubulo-lobular carcinomas had a similar average number of aberrations, rate of amplifications and losses and gains of $16 \mathrm{q}$ and $1 \mathrm{q}$ respectively. The grade 2 tumours contained an average of 6.4 aberrations with $25 \%$ showing amplifications. The chromosome regions most commonly affected were 1q (65\%), 3q (25\%), 8p (25\%), 8q (21\%), 13q (20\%) and 16q (55\%). The poorly differentiated grade 3 tumours averaged 8.4 aberrations per case, $38 \%$ revealing amplifications. The most frequent chromosomal alterations were losses of $8 p(46 \%)$ and $13 q(31 \%)$ and gains of $1 q(88 \%)$, $3 q(34 \%), 8 q(73 \%), 17 q(46 \%)$ and 20q(31\%).FISH analysis on three grade 3 ductal carcinomas with $16 \mathrm{q}$ losses demonstrated aneuploidy and in one case amplification of 11q13. Losses at 16q were predominantly found in hormone-positive tumours whereas oestrogen receptor-negative tumours showed gains of 1q,3q,8q,17qand 20q and losses of 13q.

\section{Discussion}

The existing classification of invasive breast cancer is reflected by specific combinations of quantitative and qualitative genetic changes. In addition, the distinct subtypes of breast cancer show genetic alterations that are similar to those observed in DCIS subtypes classified according to nuclear grade and cell polarisation. Losses of $16 \mathrm{q}$ and gains of 1q are associated with well differentiated DCIS and invasive carcinoma, whereas gains of $11 \mathrm{q} 13$ and $17 \mathrm{q} 12$ are associated with poorly differentiated DCIS and invasive carcinoma. 


\section{References}

1. Buerger H, Otterbach F, Otterbach F : Different genetic pathways in the evolution of invasive breast cancer are associated with distinct morphological subtypes. J Pathol. 1999, 189 : 521-526. 